\title{
nature
}

biotechnology

\section{PhRMA wants you!}

The biotech brand is in danger of being sullied by the blurring of pharma and biotech boundaries.

Eat arly last month, the Pharmaceutical Research and Manufacturers of -America (PhRMA) trumpeted that its drive to diversify membership had led to the recruitment of seven biotech firms. The drive began last July, shortly after Roche announced that it was leaving PhRMA and joining the Biotechnology Industry Organization (BIO), characterizing itself as "the world's largest biotechnology company." Tit-for-tat membership battles of healthcare lobby groups are usually of little importance. However, the status that Roche attaches to its biotech identity and the pursuit of biotech firms by PhRMA suggest that the 'biotech' brand has a distinct and desirable cachet.

The pharmaceutical industry does have a public relations problem. A Harris poll from August 2009 found that $84 \%$ of US adults blame the pharma industry for the problems with the US healthcare system. Trust ratings for pharma are also low, with only $7-14 \%$ of US adults willing to believe company statements as true (Harris Polls, 2003-2007). In contrast, attitudes toward the biopharmaceutical sector are generally positive. An April 2009 survey from the state industry association, MassBio, for instance, found $51 \%$ of voters had positive feelings towards biotech.

So 'biotech' is young, thrusting, optimistic and tackling healthcare through research while 'pharma' is gigantic, profiteering, world-worn and tackling healthcare by increasing market share. In reality, of course, no such clear-cut divisions exist. The biotech and pharma sectors form parts of a continuum, indivisible by the presence or absence of biologics, size, research concentration, clinical competence, greed or vulnerability to acquisition.

Readers may be surprised to learn that Roche is more of a biologics company than a drug company: in 2009, $54 \%$ of its revenues came from biologics and only $24 \%$ from small molecules. Other pharmaceutical companies have been developing and acquiring biologics competence at an increasing rate over the past decade or so. Pfizer's acquisition of Wyeth last October was motivated partly by the need to have more biologics. Conversely, a significant portion of the pipeline of Amgen and Genzyme is small molecules.

The blurring of the biotech-pharma boundary has led to convergent evolution of lobby groups. PhRMA's current mission is advocacy on behalf of "pharmaceutical/biotechnology research companies" while BIO's is to be "the advocate for its member organizations_-both large and small." Little to choose between the two.

There is, however, one very important difference. Whereas PhRMA has 34 full members, BIO has 1,200 members, most of which pay only nominal fees. BIO is thus the only advocate for the smaller, younger, nonrevenuedriven companies. Its voice on behalf of smaller firms may not always be loud and clear, but it is surely a voice.

By donning the 'biotech mantle', PhRMA may be hoping to capture for its members some of the public and political sympathies enjoyed by BIO. In the face of this direct competition, BIO needs to make a choice. It can out-PhRMA PhRMA, becoming a better advocate for large pharma, trying to be all things to all companies. Or it could differentiate itself by becoming an out-and-out advocate for small to medium-sized biotech, deemphasizing the large company agenda and rededicating itself to the innovative edge of the industry. We hope they choose the second path.

\section{Impossible fixes}

\section{Impractical solutions to European biotech financing don't help anyone.}

$\triangle$ couple of months ago, the European Commission and the industry Atrade association European Biopharmaceutical Enterprises held a closed meeting in Brussels to discuss a survey from ECORYS (Rotterdam), the Danish Technological Institute (DTI: Taastrup) and three other consultants undertaken as part of a $€ 2.99$ (\$4.22) million contract from the Commission (see p. 110). The survey pointed to three (obvious) funding gaps during biotech development. It also estimated that $40 \%$ of European biotechs needed more cash before the end of 2010. Urgent problems, indeed, requiring urgent solutions. So what did the report recommend?

First, it proposed that the European Commission should consider sector-specific policy measures targeting the biopharmaceutical sector. In a rational world, this is plausible and sensible. But the European Union is not rational. It is an aggregation of formerly warring nation states each seeking economic advantages while acting out historical resentments through petty and circular administrative fine-tuning. To counter the nationalistic tendencies, the European Commission's competitiveness legislation forbids governments from instituting sector-specific incentives for industry. Nations can support companies that are small or young or research intensive, but they cannot single out specific sectors, like IT or biotech, for specific help. Short of overhauling the entire philosophy of the European endeavor, this recommendation, therefore, is a non-starter.

A second proposal in the report suggests that national and European policy makers should reform the financial markets across Europe to allow venture capitalists to operate across national borders. Again, nice idea, but a pipe dream. In the main, the European Union has 27 distinct financial systems with 27 national regulatory systems and asynchronicity throughout its multiple economic cycles. This, too, is a solution for the next decade or beyond.

Thankfully, by the time it went to press, the report had been stripped of suggestions that European biotech should be financed using gold bars from the croc at the end of the rainbow or getting Sir Bob Geldof and Bono to organize a Bio-Aid telethon. European biotech financing is a tough problem in need of imaginative solutions. But solutions must be practical—not outside the realms of reality. 